\title{
Algorithm for the Formation Production Rules from Cognitive Models
}

\author{
Dmitrii Pesterev \\ Melentiev Energy Systems Institute of Siberian Branch of the Russian Academy of Sciences \\ Irkutsk, Russia \\ pesterev.dmitriy@gmail.com
}

\begin{abstract}
The article is devoted to the issue of using cognitive modeling to study energy security problems. Such concepts as cognitive modeling, cognitive model, cognitive map are introduced. The task of automating the analysis of a cognitive map with the use of technology of production expert system. To automate the conversion of cognitive map into rules of production expert system, the author proposes to use the author's algorithm, as well as to upgrade the existing tool. Implementation of the proposed approach will ensure an automatic transition from a graphic cognitive map to the construction of production rules. In conclusion, the author gives an illustrative example based on a cognitive map constructed with the involvement of energy specialists.
\end{abstract}

Keywords—energy security, cognitive modeling, expert systems.

\section{INTRODUCTION}

The fuel and energy complex (FEC) of the country is the basis of the economy. The FEC provides the vital activity of its industries, taxes on the sale of hydrocarbons are a large item of income in the budget of the Russian Federation. Given the importance of the role of energy in the development and existence of the state, energy security (ES) is one of the most important components of the economic and national security of Russia [1]. ES is the state of protection of citizens, society, the state, and the economy from deficit threats caused by internal and external factors in providing their reasonable energy needs with economically available fuel and energy resources of acceptable quality under normal conditions and in emergency situations, as well as from violations of stability and uninterrupted fuel - and power supply [2]. To ensure energy security, it is necessary to investigate the possible causes of various effects or the main threats, the implementation of which are the impact on energy systems [1]. The author suggests expanding the range of tools used for this purpose by attracting a cognitive modeling apparatus.

\section{TECHNOLOGY OF CONVERTING FROM COGNITIVE MAPS TO PRODUCTION RULES}

Cognitive modeling refers to the construction of cognitive models or, alternatively, cognitive maps (oriented graphs) in which vertices correspond to factors (concepts) and arcs correspond to positive or negative relationships between factors depending on the nature of the causal relationship. Cognitive modeling is widely used both in Russia [3] and abroad [4-6], but mainly in such poorly structured areas as sociology, economics, and medicine. It is worth noting that cognitive modeling has been recognized by energy specialists, and has also found application in the work they perform, in particular in [7]. In studies of ES problems [8], cognitive modeling is used for situational analysis of the ES problem and modeling ES threats, which are understood as adverse events for the energy sector. So far, the analysis and all conclusions on cognitive maps are carried out by the expert exclusively by hand. To automate the analysis,

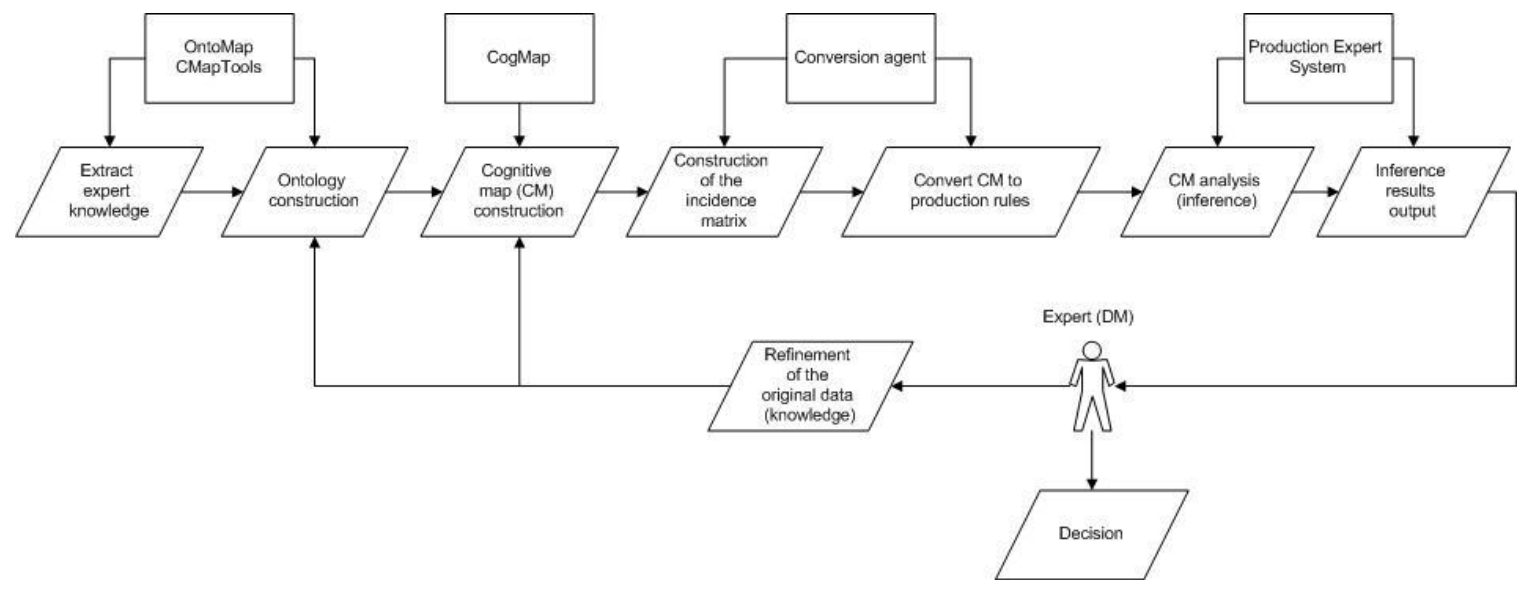

Fig.1 Technology of converting from cognitive cards to production rules 
a technology has been developed for the converting from cognitive maps to production rules (Fig. 1).

Currently, all conclusions regarding the mutual influence of cognitive map concepts can be carried out exclusively by hand, as a result of which errors may appear as a result of the analysis. Automation of the analysis of cognitive maps requires the creation of tools that will use the capabilities of the output machine of a production expert system.

The idea to use the output machine of an expert system based on products is justified by the fact that the relations between the concepts of a cognitive map can be described in the form of production rules (rules like "If ... Then ..."). These rules, describing a particular cognitive map, in turn, can be organized as a fragment of a knowledge base. It is assumed that a preliminary analysis of the cognitive map and conclusions on a set of rules will be carried out through an expert system, and an expert researcher can subsequently analyze and / or adjust these conclusions.

In the proposed technology, the CogMap tool is used to construct a cognitive map of the studied energy security problem. To use this tool in this technology, its modification was carried out, which is based on the results of ontological engineering. As part of the ontology system, the author developed the initial ontology for cognitive modeling, structuring the basic concepts used in cognitive models [9] (Fig. 2).

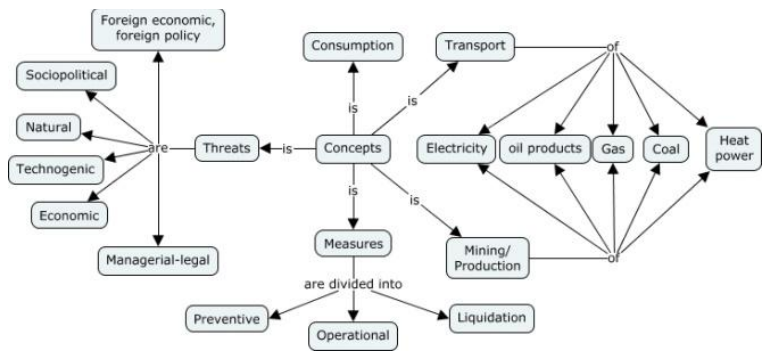

Fig. 2. Initial ontology for cognitive modeling

Each concept belongs to a certain group and has its own set of characteristics and parameters. Each group is characterized by its own "icon" in the graphical interface. The CogMap interface in an illustrative example of a cognitive model is shown in Figure 3.

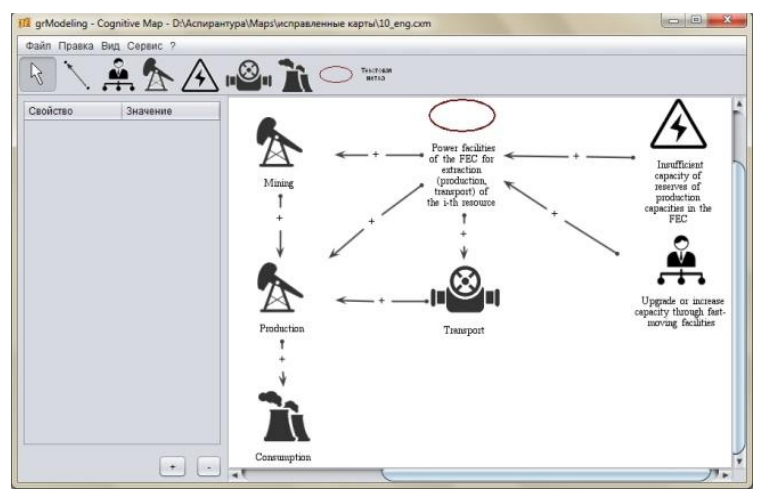

Fig. 3. Modified CogMap Interface

Also, a module for saving the cognitive map in the format necessary for transferring it to the input of the conversion agent was integrated into the CogMap tool, which, in accordance with the author's algorithm, converts the map into a set of production rules for the expert system.

\section{AN ALGORITHM FOR CONVERTING A COGNITIVE MAP INTO PRODUCTION RULES}

To convert a cognitive map into production rules, the proposed technology uses an agent that implements the author's algorithm and forms a set of production rules in the format necessary for the shell to perceive the production expert system.

The algorithm according to which the conversion is performed consists of two parts, the first (Fig. 4) is a graph traversal and an incidence matrix construction, the second part (Fig. 5) implements the matrix passage and the formation of a set of production rules.

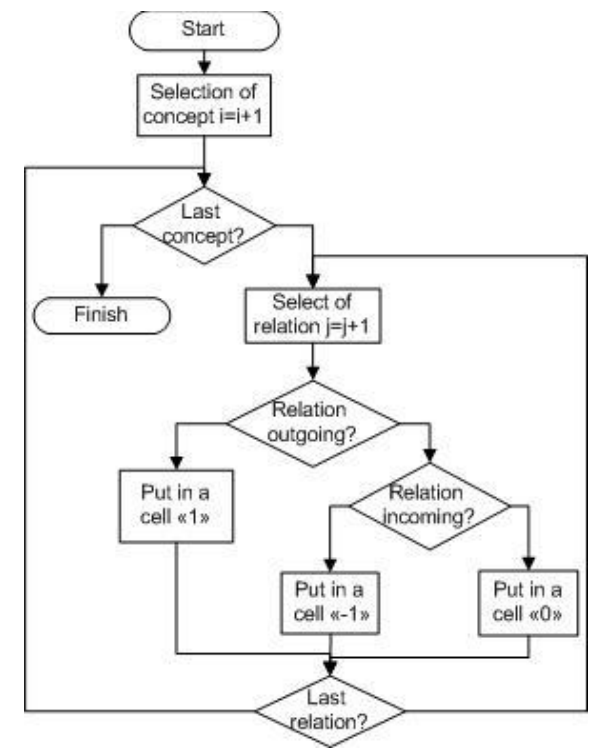

Fig. 4. Algorith of incidence matrix construction

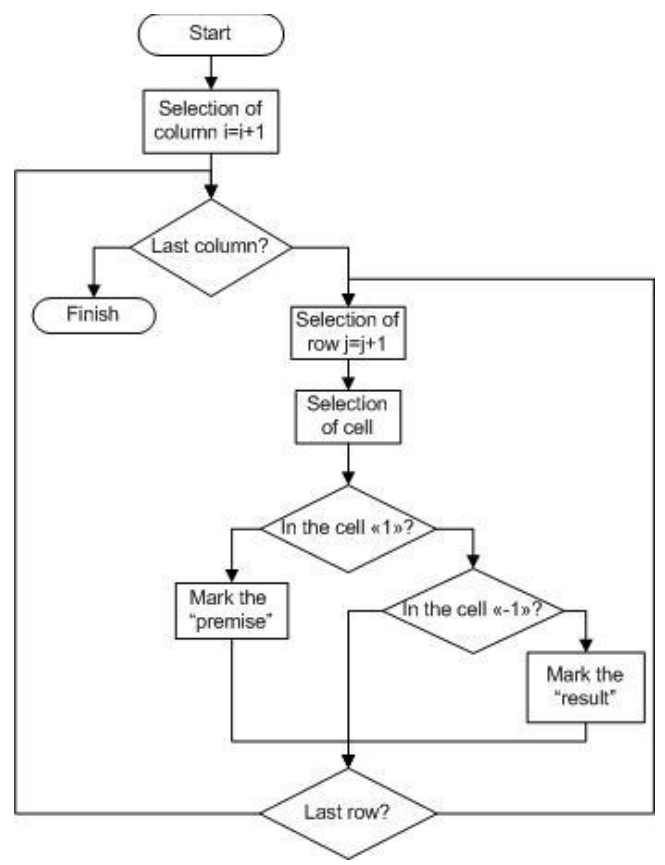

Fig. 5. Algorithm of formation of a set of production rules 
In Fig. 6. a fragment of the cognitive map, taken to illustrate the proposed approach. Each concept card has a designation of the form "Ci", where " $\mathrm{i}$ " is the serial number of the concept. These notations are introduced for the convenience of perception and for illustration purposes.

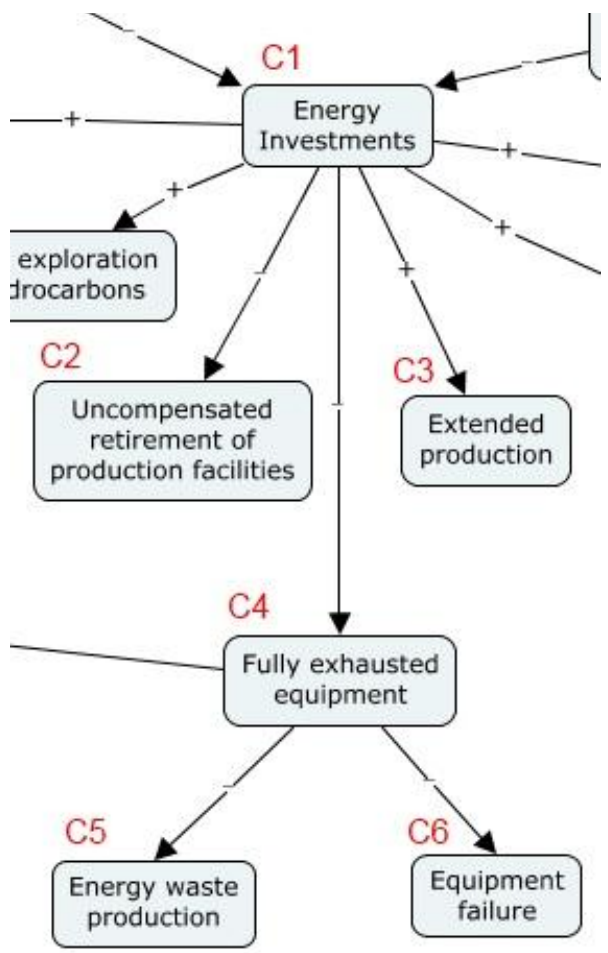

Fig. 6. Fragment of cognitive map

The incidence matrix will have the following form (Tab. 1)

TABLE I. FRAGMENT OF THE INCIDENCE MATRIX

\begin{tabular}{|l|l|l|l|l|l|l|}
\hline & $\mathrm{C} 1$ & $\mathrm{C} 2$ & $\mathrm{C} 3$ & $\mathrm{C} 4$ & $\mathrm{C} 5$ & $\ldots$ \\
\hline $\mathrm{C} 1$ & & -1 & 1 & -1 & 0 & $\ldots$ \\
\hline $\mathrm{C} 2$ & 0 & & 0 & 0 & 0 & $\ldots$ \\
\hline C3 & 0 & 0 & & 0 & 0 & $\ldots$ \\
\hline C4 & 0 & 0 & 0 & & -1 & $\ldots$ \\
\hline C5 & 0 & 0 & 0 & 0 & & $\ldots$ \\
\hline$\ldots$ & $\ldots$ & $\ldots$ & $\ldots$ & $\ldots$ & $\ldots$ & \\
\hline
\end{tabular}

The following is a snippet of the list of production rules for the given cognitive map example:

- deffunctionask(?question)

(printoutt?question)

(bind?answer(read))

?answer

)

- (defruleC1UPF

"C1stalobolshe"

(C1UP)

$=>$

(printoutt"C1stalobolshe"crlf)
(assert(C2Down))

(assert(C3UP))

(assert(C4Down))

(assert(C17UP))

(assert(C18UP))

(assert(C20UP))

(assert(C21UP))

)

- (defruleC1DownF

"C1stalomen'she"

(C1Down)

$\Rightarrow$

(assert(C2UP))

(assert(C3Down))

(assert(C4UP))

(assert(C17Down))

(assert(C18Down))

(assert(C20Down))

(assert(C21Down))

(printoutt"C1stalomen'she"crlf)

)

\section{CONCLUSION}

Currently, when the value of expert assessments, as well as the use of an intelligent instrumental apparatus, increases, the proposed technology will help the decision maker (DM) to perform analysis on cognitive maps. This will be of particular importance when the analysis is complicated by the large dimension of the cognitive map. This technology will give decision makers a set of data about the subject area, they will make the final decision, or existing knowledge will be clarified, which in the future will allow to perform even better analysis within the framework of the subject area.

\section{ACKNOWLEDGMENT}

The results presented in this paper were obtained with the partial financial support by of the state order of MESI SB RAS № AAAA-A17-117030310444-2 and by RFBR grants : № 19-07-00351 А и №18-0700714 A, №17-07-01341

\section{REFERENCES}

[1] S.P. Filippov et al., System Studies of Energy Problems. Ed. by N.I. Voropai, Novosibirsk, Russia: Nauka. Publishing Company of RAS, 2000, p. 588. C.П. [Sistemnye issledovaniya problem energetiki. pod red. N.I. Voropaya, Novosibirsk, Rossiya: Nauka. Izdatel'skaya firma RAN, 2000, s 588.] (In Russian)

[2] N.I. Pyatkova et al., Energy Security of Russia: Problems and Solutions, Novosibirsk, Russia: Publishing House of SB RAS, 
2011, p.198. [Energeticheskaya bezopasnost' Rossii: problemy i puti resheniya, Novosibirsk, Rossiya: Izdatel'stvo SO RAN,2011, s198.] (In Russian)

[3] Avdeeva Z., Kovriga S.. Heuristic method of conceptual structuring of knowledge in the formalization of semistructured situations on the basis of cognitive maps. M.: ICS RAS. - Managing large systems.- 2010.- №31.- pp. 6-34. [Evristicheskij metod konceptual'noj strukturizacii znanij pri formalizacii slabostrukturirovannyh situacij na osnove kognitivnyh kart. - M.: IPU RAN. - Upravlenie bol'shimi sistemami.- 2010.- №31.- S. 6-34.] (In Russian)

[4] P.Groumpos and C. Stylios, "Modelling supervisory control systems using fuzzy cognitive maps", Chaos, Solitons \& Fractals, vol. 11, no. 1-3, pp. 329-336, 2000

[5] E. Papageorgiou, C. Stylios and P. Groumpos, "An integrated two-level hierarchical system for decision making in radiation therapy based on fuzzy cognitive maps", IEEE Transactions on Biomedical Engineering, vol. 50, no. 12, pp 1326-1339, 2003.

[6] P. Groumpos and A. Anninou, "A theoretical mathematical modeling of Parkinson's disease using Fuzzy Cognitive Maps", in Bioinformatics \& Bioengineering (BIBE), IEEE 12th International Conference on. IEEE, 2012, pp 677-682.

[7] N.I. Pyatkova, G.B. Slavin, E.V. Pyatkova, "Insufficient level of investment in the energy sector is one of the strategic threats to the national energy security", Proceedings of the Russian Academy of Sciences. Power Engineering, No. 2, p. 42-48, 2015. [Nedostatochnyj uroven' investicij $\mathrm{v}$ otraslyah TEK - odna iz strategicheskih ugroz energeticheskoj bezopasnosti strany / Izvestiya Rossijskoj akademii nauk. Energetika. 2015. № 2. - S. 42-48.] (In Russian)

[8] Massel' L.V., Massel' A.G. Technologies and tools of intelligent decision-making support of in emergency situations in the energy sector / Computational technologies. 2013.- T.18.- Special vol. - pp. 37-44. [Tekhnologii i instrumental'nye sredstva intellektual'noj podderzhki prinyatiya reshenij v ekstremal'nyh situaciyah v energetike / Vychislitel'nye tekhnologii. - 2013.- T.18.- Special'nyj vypusk. - S. 37-44] (In Russain)

[9] Massel A.G., Pesterev D.V. Transformation of cognitive models into knowledge base of production expert system // Proceedings of the 19th International Workshop on Computer Science and Information Technologies. Germany, BadenBaden. Publisher Ufa: USATU. Vol. 1. 2017. - Pp. 121-124. ISBN 978-5-1030-8, ISBN 978-4-4221-1031-5 (v. 1) 